\title{
Ground Validation Experiment and Spectral Detection Capability Evaluation of Mars Mineralogical Spectrometer (MMS) Aboard HX-1 Orbiter
}

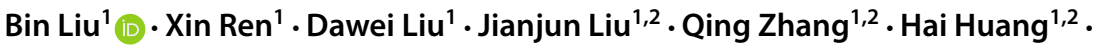 \\ Rui $\mathrm{Xu}^{3} \cdot$ Rong Wang ${ }^{3}$. Chengyu $\mathrm{Liu}^{3} \cdot$ Zhiping $\mathrm{He}^{3} \cdot$ Chunlai $\mathrm{Li}^{1,2}$
}

Received: 20 January 2021 / Accepted: 16 October 2021 / Published online: 29 December 2021

(c) The Author(s) 2021

\begin{abstract}
As a hyperspectral imager aboard the orbiter "HX-1" of China's first Mars mission, the Mars Mineralogical Spectrometer (MMS) is designed with hyperspectral and multispectral operation modes to survey the mineral types and their distribution on the surface of Mars, and to study the overall chemical composition and evolution history of Mars. The multispectral modes of MMS are different from hyperspectral modes on the bands selection, spatial and spectral resolution, Signal-to-Noise Ratio (SNR) etc. So the spectral detection capability of each mode of MMS is also different. The ground validation experiment of MMS is conducted to evaluate the hyperspectral and multispectral data quality and detection capabilities. The main conclusions include: (1) The measured hyperspectra of typical mineral samples obtained by MMS agree well with the data acquired by the Standard Comparison Spectrometers (SCS) under the same measurement conditions, and the spectral uncertainty between MMS and SCS is less than 7\% in the key spectral ranges $(0.7 \sim 2.2 \mu \mathrm{m})$. For some typical minerals, the absorption band positions deviation between MMS and SCS are within $0.69 \sim 14.86 \mathrm{~nm}$, which are within the spectral resolution limits of MMS. (2) The six sets of band combinations designed for MMS multispectral modes are slightly superior to CRISM's multispectral mode in terms of spectral resolutions and bands selection, the water-containing minerals will be more accurately distinguished and identified, such as montmorillonite and kaolinite. Besides, the SNR of each multispectral mode is greater than 400 in the 500-2600 $\mathrm{nm}$ spectral range, which meets the requirements for the subtle spectral characteristics of water-containing minerals. (3) Benefiting from the MMS ground validation experiment and the experience of the OMEGA and CRISM, it is recommended that MMS first adopt the spatial continuous 52-sample or 104-sample (spatial resolution is about $0.53 \sim 1.06 \mathrm{~km}$ ) multispectral operation mode for typical minerals global mapping and finding target areas of interest. Then the 208-sample multispectral mode (spatial resolution is about $\sim 265 \mathrm{~m}$ ) or 26-sample hyperspectral mode can be used to survey target areas of interest for the subtle mineral types characteristics and distribution. At last, 26-sample hyperspectral mode could be used to monitor the atmospheric composition of Mars by limb observations.
\end{abstract}

The Huoxing-1 (HX-1) / Tianwen-1 (TW-1) mission to Mars

Edited by Chunlai Li and Jianjun Liu

Extended author information available on the last page of the article 
Keywords China's first Mars mission · HX-1 - Mars Mineralogical Spectrometer (MMS) Spectral detection capability $\cdot$ Ground validation experiment

\author{
Abbreviations \\ CAS Chinese Academy of Sciences \\ EQM Engineering Qualification Model \\ GRAS Ground Research and Application System \\ HCP High-Calcium Pyroxene \\ IFOV Instantaneous Field of View \\ LCP Low-Calcium Pyroxene \\ MMS Mars Mineralogical Spectrometer \\ NAO National Astronomical Observatories \\ NIM National Institute of Metrology \\ N-MIR Near-infrared and Mid-infrared \\ REFF Reflectance Factor \\ SITP Shanghai Institute of Technical Physics \\ SNR Signal to Noise Ratio \\ SCS Standard Comparison Spectrometer \\ V-NIR Visible and Near-Infrared
}

\title{
1 Introduction
}

The evolution history of Mars is preserved in the rocks and sediments on its surface, and the composing minerals and structural characteristics of Martian rocks record their formation conditions and history (Ehlmann and Edwards 2014). In the past 40 years, following earlier telescopic observations (e.g., Pinet and Chevrel 1990; Martin et al. 1996), hyperspectral remote sensing serving as an effective tool for the identification and mapping of Martian surface minerals (Farmer 1974; Clark 1995; Bibring et al. 2005; Murchie et al. 2007) has significantly advanced our understanding of the composition and evolution history of Mars, especially benefiting from the data acquired by OMEGA launched by ESA in 2003 and the CRISM launched by NASA in 2005. These two hyper-spectrometers are still working and have acquired a large number of scientific results. For example, OMEGA has identified and mapped the distribution of mafic minerals that are widely present in the northern plains and southern highlands of the martian surface, and found the areas that are enriched phyllosilicates and sulfates but with no carbonates (Bibring et al. 2005). CRISM has expanded the detection of OMEGA, key results include the identification of more different types of sediment areas rich in hydrated minerals, discovery of widely distributed phyllosilicates in the early to middle Noachian period, conformation of the existence of carbonates in the bedrock for the first time, and the characterization and monitoring of seasonal changes in the composition of the polar regions of Mars (Murchie et al. 2009). Nevertheless, many new questions and puzzles have also been proposed at the same time based on the above-mentioned scientific results, which need to be solved by subsequent explorations (Ehlmann and Edwards 2014). For example, although it was known that the oldest Noachian crust on the surface of Mars is basaltic, the relative proportions of its lava bedrock, volcanic ash, impact breccias, sediments and chemically weathered material are still unclear. Besides, a large number of phyllosilicate sediments are only found in the Noachian crust (Bibring et al. 2006), and we know very little about the extent of this hydrated alteration. Moreover, the composition of some important geological units on Martian surface is poorly known currently. Finally, 
more accumulation of atmospheric spectral data on spatial and temporal changes are required for the characterization and monitoring of Martian atmosphere. MMS is equipped on HX-1 orbiter with the hope of resolving these questions (Ye et al. 2017; Li et al. 2018; He et al. 2021). Compared with OMEGA and CRISM, MMS has its own characteristics in the instrument design and spectral detection capabilities. Firstly, MMS possesses hyperspectral detection modes, the spectral range of MMS covers from $0.38 \mu \mathrm{m}$ to $3.4 \mu \mathrm{m}$, and the spectral resolution can reach $3.51 \sim 9.66 \mathrm{~nm}$, which could identify and discriminate subtle spectral changes of most mineral types of Mars. Secondly, considering the constraints on data transmission and downlink (The downlink data transmission rate of the HX-1 orbiter will change between 128 and $4096 \mathrm{Kbps}$ depending on the distance between the orbiter and the Earth), MMS designed many multispectral detection modes which could optimize the data volumes by spatial $2 * 2,4 * 4,8 * 8$ or $16 * 16$ pixels binning, spectral pixels binning $(2 * 2)$ and key wavelengths selection (six sets of 72 multispectral bands selected from 576 hyperspectral bands) (He et al. 2021; Liu et al. 2018). However, due to the differences existed in the band settings (bands selection and sampling intervals), the spectral resolution and the SNR among different operation modes of MMS (hyperspectral mode and all six sets of multispectral modes), the spectral detection capabilities of the MMS in different modes are also different. So it requires corresponding validation experiment on the ground to investigate and evaluate the spectral detection capabilities of MMS in different detection modes, which could also provide guidance for MMS in-flight detection strategies.

Spectral detection capability refers to the qualitative and quantitative evaluations of the spectrometers' capabilities for the identification and discrimination of typical minerals. As the spectral resolution and the numbers of sampling bands improved, many features of minerals should be observed, which will enhance the capacity of the spectrometer in distinguishing subtle spectral changes of different minerals and even helps to determine the chemical composition of the minerals (Clark et al. 1990). However, the enhancement of the spectral resolution and sampling bands does not necessarily ensure an improvement of the spectrometer's spectral detection capability, since the bands SNR decreases simultaneously. Therefore, the spectral detection capability of a spectrometer should be evaluated before launch. We have known that OMEGA and CRISM have clearly identified and mapped a large number of minerals on martian surface, which mainly include primary diagenetic minerals (e.g. Low-Calcium Pyroxene (LCP), High-Calcium Pyroxene (HCP) and olivine), sulfides (e.g. pyrite and pyrrhotite), and oxide minerals (e.g. magnetite and ilmenite). Secondary minerals have also been found on the surface of Mars including oxide minerals (e.g. hematite andgoethite), phyllosilicates (e.g. Fe/Mg smectites, $\mathrm{Al}$ smectites, kaolin group minerals, and serpentine), sulfates (e.g. gypsum and jarosite) and other hydrated minerals (Ehlmann and Edwards 2014). However, the absorption features of some mineral phases currently detected by OMEGA and CRISM are very tentative, Cautions should be made on the identification and mapping of these minerals phases such as talc (Viviano et al. 2013), vermiculite, margarite, epidote and etc. (Carter et al. 2013). Carter et al. (2013) also pointed out that the band numbers of OMEGA and CRISM for the effective identification of hydrous minerals' characteristics should be at least 5-8 and 9-15. But the spectral sampling interval of CRISM global mode is about $56 \mathrm{~nm}$, such a wide sampling interval will cause the number of bands to be no more than 4 for hydrous minerals identification, which make it difficult to accurately capture the absorption features of hydrous minerals on martian surface. Although the spectral resolution of the MMS hyperspectral mode is comparable to CRISM, the spectral intervals of MMS multispectral mode is better than that of CRISM global mode. Theoretically, MMS could be more accurate than CRISM in identifying and discriminating spectral characteristics of minerals in global mode, but it is still necessary to evaluate the 
Fig. 1 The working principle of MMS. The data volumes could be optimized by spatial $2 * 2,4 * 4$, $8 * 8$ or $16 * 16$ pixels binning, spectral pixels binning $(2 * 2)$ and 72 key wavelengths selection

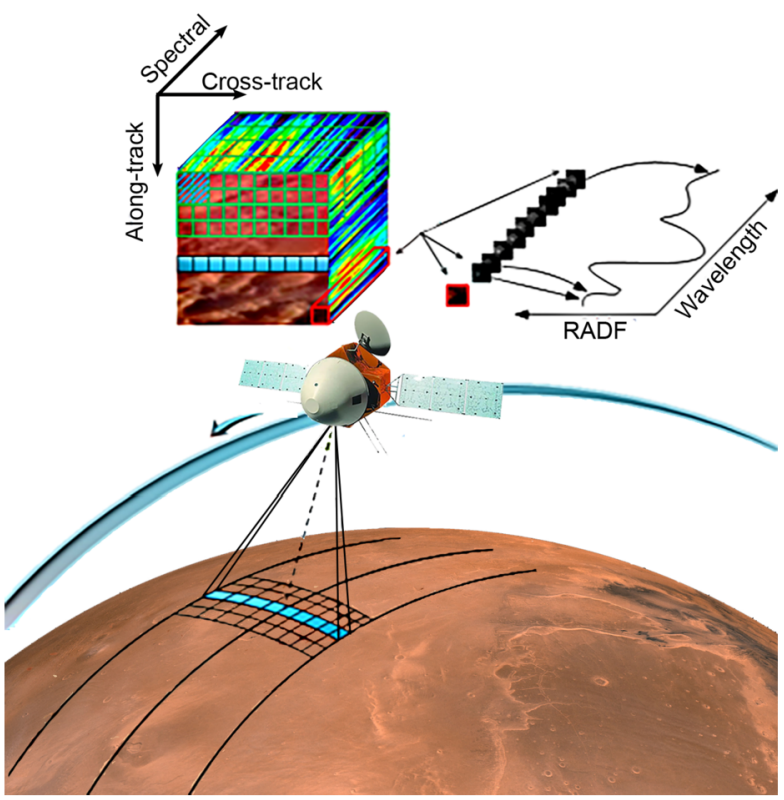

hyperspectral and multispectral spectral detection capabilities of MMS by ground validation experiment.

This paper first summarizes the main technical parameters and operation modes of MMS, and then introduces the ground validation experiment. By selecting representative samples, the samples' hyperspectral and multispectral data of MMS and the data of the SCS measured under the same conditions are compared in the aspects of spectral shape, magnitude, absorption band centers, etc. And the spectral uncertainties are calculated to quantitatively evaluate data quality of MMS hyperspectral mode and multispectral mode. Finally, combined with the quantitative analysis of MMS' parameters such as the spectral range, spectral resolution, bands selection, and signal-to-noise ratio, the spectral detection capabilities of MMS are evaluated and the in-flight detection strategies are suggested and discussed.

\section{Overview of MMS}

MMS is a pushbroom imaging spectrometer developed by the Shanghai Institute of Technical Physics, Chinese Academy of Sciences (CAS). Its Instantaneous Field Of View (IFOV) is $0.5 \mathrm{mrad}$, and the spectral range covers from 0.379 to $3.425 \mu \mathrm{m}$ in 576 contiguous bands. MMS contains two spectrometers, one is a Visible and Near-infrared spectrometer (V-NIR, $0.379 \sim 1.076 \mu \mathrm{m}$ ), and the other is a Near-infrared and Mid-infrared spectrometer (N-MIR, $1.033 \sim 3.425 \mu \mathrm{m})$. The solar radiation reflected by the Martian surface in a line region is imaged at the slit, and MMS obtains the image information in cross-track direction and acquires the spectral information by splitting the light in the spectral direction (Fig. 1). Pushbroom imaging is realized through the movement of the orbiter to acquire the along-track spatial and spectral information. Detailed introduction of MMS can be referred to He et al. (2021).

The HX-1 orbiter has an elliptical orbit with the minimum altitude of $265 \mathrm{~km}$ on the perigee and the maximum altitude of $\sim 11943 \mathrm{~km}$ on the apogee. MMS will start to work 
Table 1 The six sets of multispectral band combinations of MMS for minerals identification

\begin{tabular}{llll}
\hline Numbers & Typical minerals & $\begin{array}{l}\text { Six sets of band } \\
\text { combinations }\end{array}$ & Bands selection \\
\hline 1. & Versatile & Mode 1 & 19 bands for V-NIR, 52 bands for N-MIR \\
2. & Phyllosilicates & Mode 2 & 12 bands for V-NIR, 59 bands for N-MIR \\
3. & Sulfates & Mode 3 & 12 bands for V-NIR, 59 bands for N-MIR \\
4. & Carbonates & Mode 4 & 12 bands for V-NIR, 59 bands for N-MIR \\
5. & Hydrated salts & Mode 5 & 15 bands for V-NIR, 56 bands for N-MIR \\
6. & Iron oxides and silicates & Mode 6 & 23 bands for V-NIR, 48 bands for N-MIR \\
\hline
\end{tabular}

when the orbit altitude is lower than $800 \mathrm{~km}$ and the effective working time per orbit will be approximately 26 minutes. Considering the pressure on the data transmission and downlink, MMS designed many detection modes which could optimize the data volumes by spatial $2 * 2,4 * 4,8 * 8$ or $16 * 16$ pixels binning, spectral pixels binning $(2 * 2)$ and key wavelengths selection (72 multispectral bands selected from 576 hyperspectral bands (He et al. 2021; Liu et al. 2018). The multi-sample hyperspectral modes (576 bands) of MMS include: the fullframe hyperspectral mode, the spatial continuous 26-sample hyperspectral mode, and the spatial discontinuous 3-sample hyperspectral mode. The multispectral imaging modes of MMS include: the spatial continuous 52-sample, 104-sample and 208 sample multispectral imaging modes.

A great feature of MMS is the design of six sets of 72 key bands combinations (Table 1) for every multispectral detection mode (Liu et al. 2018; He et al. 2021). The versatile band combination (mode 1) can be used to identify and detect most of the Mars' surface minerals with a slightly lower accuracy, and the other five band combinations could be used with higher accuracy to identify phyllosilicate, sulfates, carbonates, hydrated salts, iron oxides and primary silicates respectively.

MMS has completed spectral calibration and radiometric calibration before launch $(\mathrm{He}$ et al. 2021). The spectral calibration error is less than $\pm 0.001 \lambda$ in the whole spectral range, and the absolute radiometric calibration errors are better than 1.9\%@ $450 \sim 1050 \mathrm{~nm}$, 5.2\%@1000 2400 nm, 4.9\%@2400 3400 nm.

\section{Experimental Contents and Results}

\subsection{Experimental Contents}

We have known that MMS has two types of spectral detection modes, one is the hyperspectral modes (576 band, high spectral resolution), and the other one is the multispectral modes (each mode contains six sets of 72 band combinations, low spectral resolution). Therefore, we mainly focus on the evaluation of the spectral data quality and detection capabilities of these two kinds of detection modes. The main experiment contents are as follows: (1) many kinds of typical minerals and mixtures' spectra are measured simultaneously by MMS hyperspectral mode and the SCS under the same geometry and lighting conditions. After that, the spectra of SCS are resampled to MMS hyperspectral data, and the data between MMS and SCS are compared by analyzing spectral shapes and magnitudes. Then the spectral uncertainty and deviations of band centers are calculated to quantitatively evaluate spectral data quality and spectral detection capabilities of MMS' hyperspectral mode. (2) the same 
Table 2 The samples selected in the experiment

\begin{tabular}{ll}
\hline Kinds of samples & Mineral selected \\
\hline phyllosilicates & chlorite \\
Mafic silicates & $\begin{array}{l}\text { hypersthene } \\
\text { apatite }\end{array}$ \\
Aqueous minerals & gypsum \\
sulfates & siderite \\
Carbonates & geothite \\
Oxides minerals & $10 \mathrm{wt} \%$ hypersthene $+90 \mathrm{wt} \%$ augite \\
Mixed sample 1 & $20 \mathrm{wt} \%$ hypersthene $+80 \mathrm{wt} \%$ augite \\
Mixed sample 2 & $30 \mathrm{wt} \%$ hypersthene $+70 \mathrm{wt} \%$ augite \\
Mixed sample 3 & $40 \mathrm{wt} \%$ hypersthene $+60 \mathrm{wt} \%$ augite \\
Mixed sample 4 & $50 \mathrm{wt} \%$ hypersthene $+50 \mathrm{wt} \%$ augite \\
Mixed sample 5
\end{tabular}

kinds of typical minerals and mixtures' spectra are measured by MMS multispectral mode under the same geometry and lighting conditions, and the spectra of two typical minerals, hypersthene and gypsum, which exhibit obvious broadband and narrowband absorptions are selected to evaluate the data quality and detection capabilities of MMS multispectral modes. All the six sets of 72 band combinations hypersthene and gypsum's multispectral data are compared with the corresponding hyperspectral data qualitatively by evaluation of the spectral shape, magnitude, band numbers and their distribution. After that, the deviation of the band centers between the multispectral and corresponding hyperspectral data are calculated quantitatively to further evaluate the minerals identification and discrimination capability of MMS multispectral modes.

During the experiment, the SCS used for data comparison are Fieldspec 4 Hi-res and DP 102F, which have been calibrated by National Institute of Metrology (NIM) of China. The spectral range of Fieldspec 4 Hi-res is $350 \mathrm{~nm} \sim 2600 \mathrm{~nm}$ with a spectral resolution of $3 \mathrm{~nm} @ 700 \mathrm{~nm}, 10 \mathrm{~nm} @ 1400 \mathrm{~nm}$ and $10 \mathrm{~nm} @ 2100 \mathrm{~nm}$, it is mainly used to simultaneously obtain and compare the 450-2500 nm spectral data with MMS. The spectral range of DP $102 \mathrm{~F}$ is $2000 \mathrm{~nm}-16000 \mathrm{~nm}$, which is used to simultaneously obtain and compare the 2000-3400 nm spectral data with MMS.

\subsection{Samples Selection}

The experiment samples should be representative for martian surface. We try to choose minerals that have been discovered or confirmed on martian surface. According to the designed 6 sets of band combinations of MMS multispectral modes, we selected 6 kinds of minerals representing different mineral groups (Table 2). All the mineral samples selected were grounded and stirred homogeneous to about 200 mesh (median particle size about $75 \mu \mathrm{m}$ ) to simulate the soil state of martian surface. In addition, a binary mixed samples of LCP (hypersthene) and HCP (augite) in different mass percents (Table 2) were prepared to test MMS' sensitivity on subtle changes of spectral shape and absorption centers. The spectra of the six powdered mineral samples and five mixed samples measured by the SCS are plotted in Fig. 2 and Fig. 3.

\subsection{Experiment Procedures}

The validation experiment is designed and implemented by the Ground Research and Application System (GRAS) of National Astronomical Observatories (NAO), CAS and the 
Fig. 2 The spectral characteristics of the six mineral samples measured by the SCS in the range of 450-3400 $\mathrm{nm}$
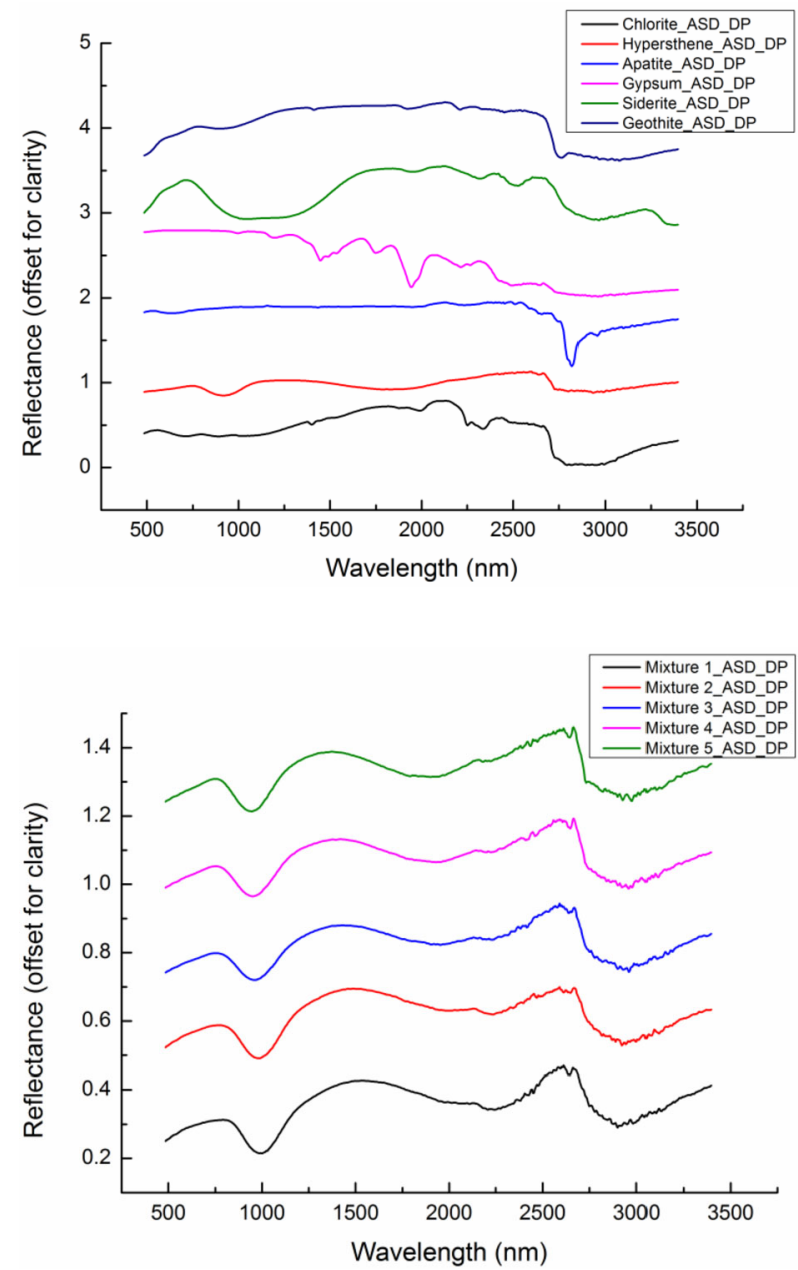

Fig. 3 The spectral characteristics of the five mixed samples measured by the SCS in the range of 450-3400 nm 


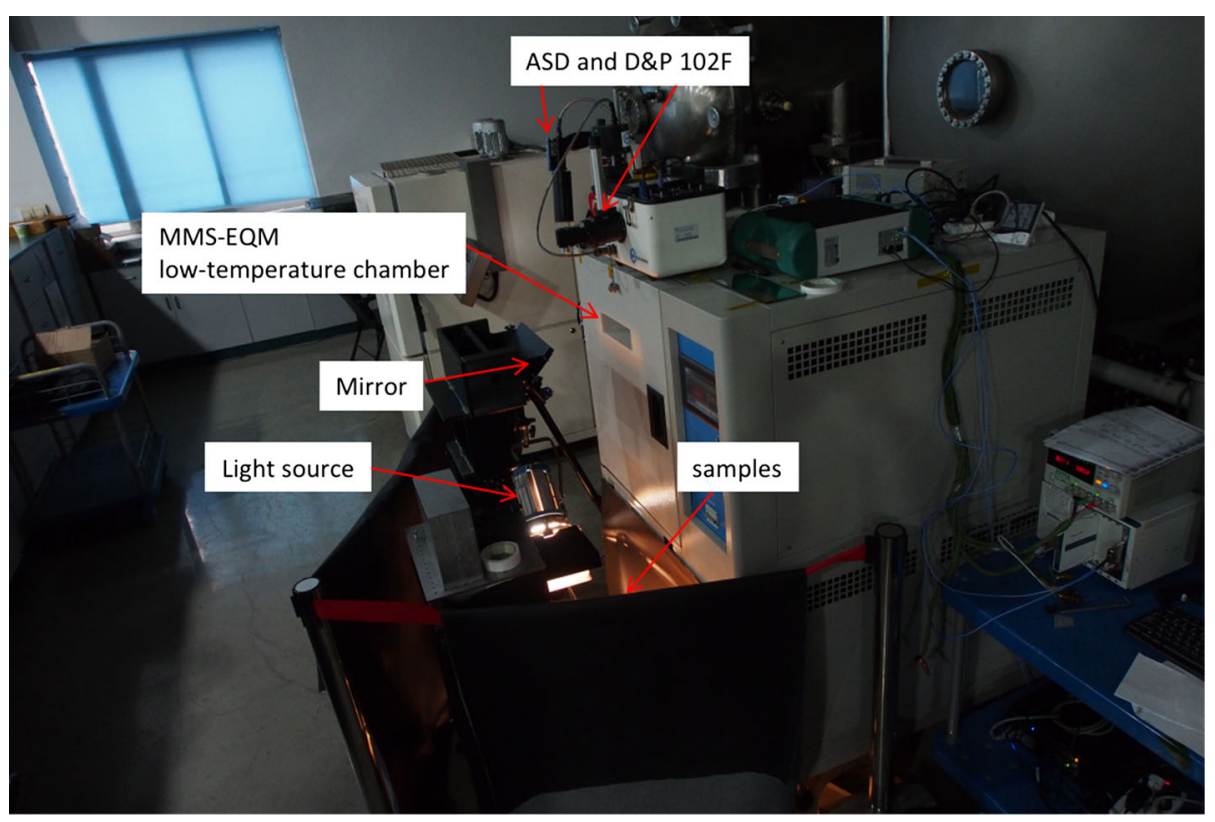

Fig. 4 The environment of the laboratory scientific validation experiment. The powdered sample or the standard reflectance panel is illuminated by the light source, MMS and the SCS received the light signal at the same time and the same geometry

reflectance (REFF) calculation (He et al. 2021; Liu et al. 2014). The Spectralon standard panels was used for 0.45-2.5 $\mu \mathrm{m}$ REFF calculation, while the Infragold standard panels was used for 2.5-3.4 $\mu \mathrm{m}$ REFF calculation. The obtained reflectance data of the SCS were resampled to MMS bandpass for further comparison. After that, the hyperspectral data quality of MMS were evaluated qualitatively by comparing spectral shape and magnitudes measured by MMS with the resampled spectra acquired by the SCS. Finally, hyperspectral data of MMS were also quantitatively evaluated by calculating the spectral uncertainty between the measured data of MMS and the SCS. The formula for calculating spectral uncertainty is as follow:

$$
\delta=\frac{\sum_{i=1}^{N}\left|\frac{S_{M M S, i}-S_{S S, i}}{S_{S S, i}}\right|}{N} \times 100 \%
$$

Here, $S_{M M S, i}$ is the sample's $i$ th band reflectance of MMS, $S_{S S, i}$ is the sample's $i$ th band reflectance of the SCS, $\mathrm{N}$ is the number of bands.

Shown in Fig. 5 and Fig. 6 are hyperspectral curves acquired by MMS and SCS for all the minerals and the mixed samples. By comparing the spectral shape and magnitudes of these two types of data, we found that the hyperspectra of the samples measured by MMS agree well with that acquired by the SCS. The statistics of spectral uncertainty (Tables 3, 4 and 5) suggest that the mean values of the spectral uncertainty for all the samples in the range of $0.7 \sim 2.2 \mu \mathrm{m}$ is less than $7 \%$, most of which are even less than $5 \%$. Besides, the mean values of the spectral uncertainty for all the samples in the range of $0.45 \sim 0.7 \mu \mathrm{m}$ and $2.3 \sim 3.4 \mu \mathrm{m}$ are still less than $14 \%$, indicating a good data quality of MMS in the entire spectral range. Nevertheless, We noted that MMS curves have a slightly lower SNR in the spectral range 

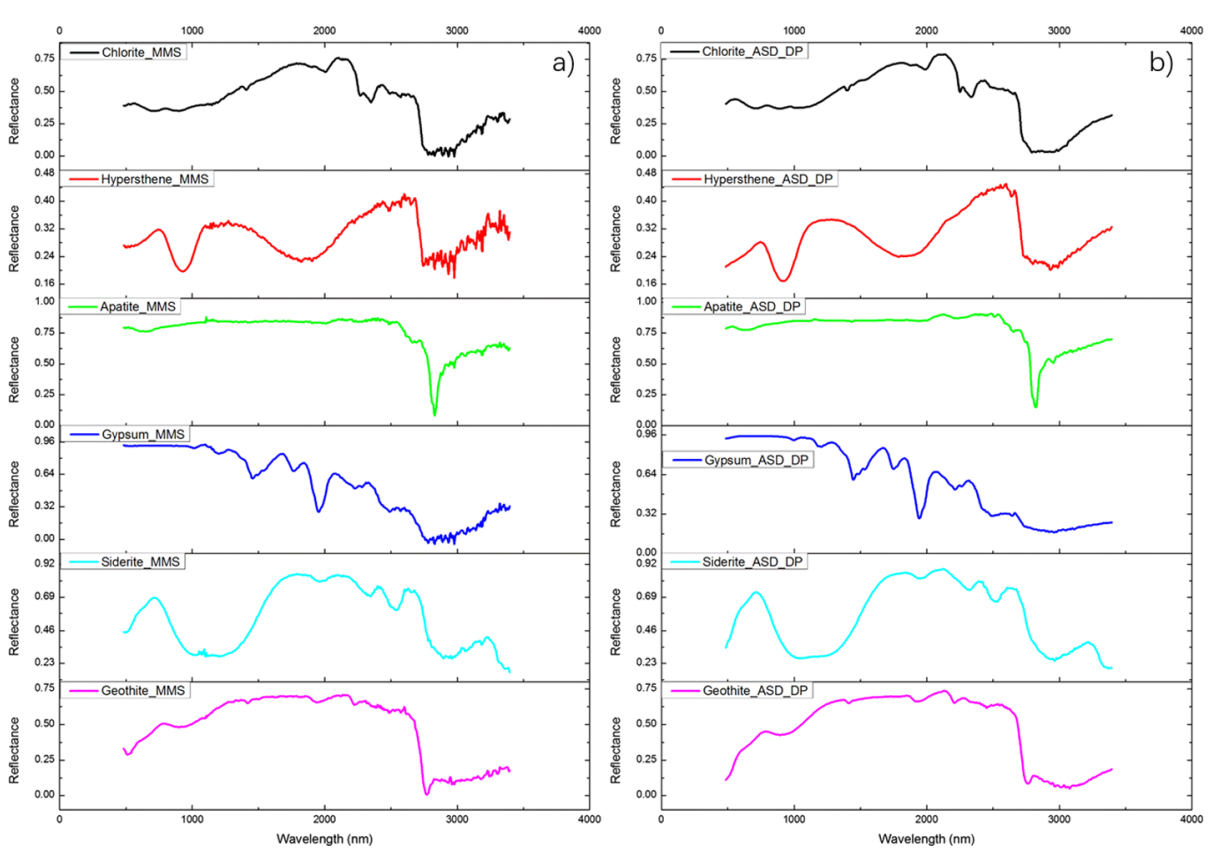

Fig. 5 The six minerals' hyperspectral data comparison results between MMS and the SCS. (a. the hyperspectra of MMS; b. the resampled spectrum of ASD and DP 102F)
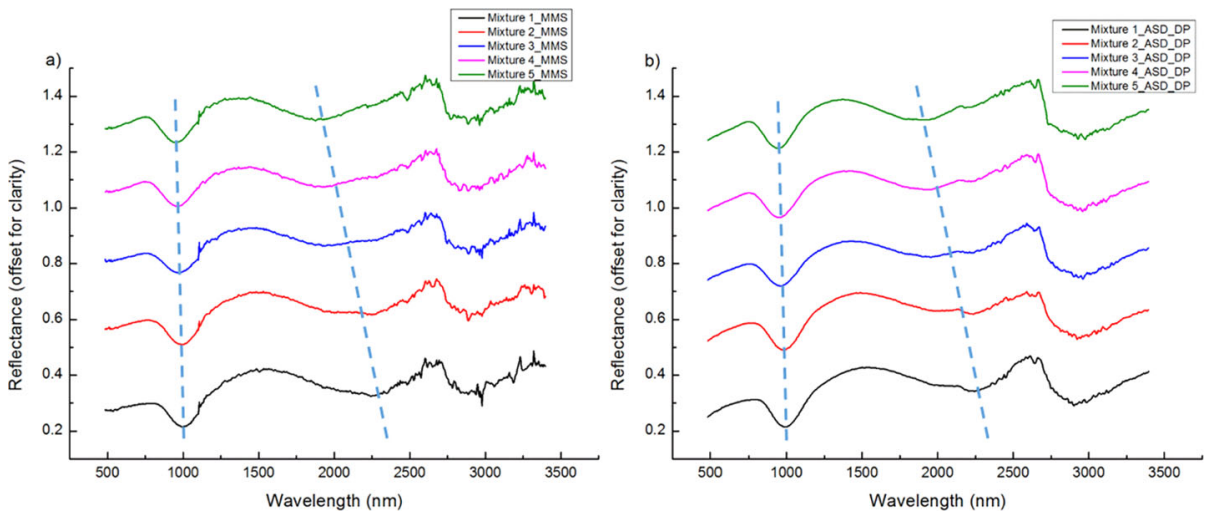

Fig. 6 The five mixed samples' hyperspectral data comparison results between MMS and the SCS. (a. the hyperspectral spectrum of MMS; b. the resampled spectrum of ASD and DP 102F. The reflectance data has been offset for clarity)

of $2.75 \sim 3.4 \mu \mathrm{m}$. Two reasons might account for this phenomenon, one is that the intensity of the laboratory light source is too weak compared to the sunlight, which decreases the SNR of MMS since the band integration times of MMS are set according to the intensity of sunlight. The other possible reason is that the reflectance data of the SCS are averaged from ten repeated measurements, but the data of MMS are not. 
Table 3 The samples' spectral uncertainty statistics in the range of 700-2200 nm

\begin{tabular}{|c|c|c|c|c|}
\hline \multirow[t]{2}{*}{ Sample names } & \multicolumn{4}{|l|}{$700-2200 \mathrm{~nm}$} \\
\hline & Mean value (\%) & Maximum (\%) & Minimum (\%) & Standard errors $(\%)$ \\
\hline Hypersthene & 6.12 & 19.73 & 0.15 & 4.78 \\
\hline gypsum & 3.90 & 16.27 & 0.09 & 2.89 \\
\hline apatite & 1.70 & 5.13 & 0.15 & 1.02 \\
\hline chlorite & 2.45 & 6.65 & 0.02 & 2.13 \\
\hline siderite & 2.67 & 21.82 & 0.01 & 3.05 \\
\hline geothite & 3.76 & 14.11 & 0.01 & 4.78 \\
\hline Mixed sample 1 & 2.71 & 7.37 & 0.06 & 1.58 \\
\hline Mixed sample 2 & 3.01 & 7.11 & 0.01 & 1.56 \\
\hline Mixed sample 3 & 4.04 & 13.94 & 0.40 & 2.24 \\
\hline Mixed sample 4 & 4.33 & 9.51 & 0.08 & 1.95 \\
\hline Mixed sample 5 & 2.36 & 8.97 & 0.04 & 1.70 \\
\hline
\end{tabular}

Table 4 The samples' spectral uncertainty statistics in the range of 450-700 nm

\begin{tabular}{|c|c|c|c|c|}
\hline \multirow[t]{2}{*}{ Sample names } & \multicolumn{4}{|l|}{$450-700 \mathrm{~nm}$} \\
\hline & Mean value $(\%)$ & Maximum (\%) & Minimum (\%) & Standard errors $(\%)$ \\
\hline Hypersthene & 11.42 & 19.37 & 6.86 & 3.98 \\
\hline gypsum & 2.08 & 2.72 & 0.26 & 0.76 \\
\hline apatite & 1.30 & 1.86 & 0.01 & 0.51 \\
\hline chlorite & 6.54 & 8.21 & 3.03 & 1.00 \\
\hline siderite & 6.93 & 33.17 & 0.28 & 7.18 \\
\hline geothite & 13.42 & 34.99 & 4.37 & 4.95 \\
\hline Mixed sample 1 & 3.01 & 10.33 & 0.14 & 2.10 \\
\hline Mixed sample 2 & 3.15 & 12.22 & 0.03 & 3.66 \\
\hline Mixed sample 3 & 3.81 & 10.09 & 0.07 & 1.95 \\
\hline Mixed sample 4 & 9.53 & 18.57 & 5.79 & 3.76 \\
\hline Mixed sample 5 & 5.55 & 13.18 & 2.46 & 2.96 \\
\hline
\end{tabular}

\subsubsection{Absorption Characteristics Analysis of MMS' Hyperspectral Data}

The hyperspectral data quality of MMS is also evaluated by identifying the characteristic absorption features of typical minerals, and by quantitatively calculating the six typical minerals' absorption band centers deviation between MMS and the SCS. The method for calculating the absorption band centers is described as follows: (1) the continuum of the six minerals' spectra is removed by ENVI Convex Hull Fit algorithm (Fig. 7). (2) quadratic polynomial fitting was used to fit the absorption band centers. The band position corresponding to the minimum value of the quadratic fitted polynomial was used as the absorption band center.

Figure 5 and Fig. 6 have shown the spectral features of all the minerals and mixtures. The spectrum of the chlorite exhibits $1.4 \mu \mathrm{m}, 1.9 \mu \mathrm{m} \mathrm{H}_{2} \mathrm{O}$ absorption features and a $2.3 \mu \mathrm{m}$ absorption feature due to $\mathrm{Fe}$ and/or $\mathrm{Mg}$ cations bonding with hydroxyl groups. Gypsum 
Table 5 The samples' spectral uncertainty statistics in the range of 2200-3400 nm

\begin{tabular}{lcllc}
\hline Sample names & \multicolumn{2}{l}{$2200-3400 \mathrm{~nm}$} & & \\
\cline { 2 - 5 } & Mean values (\%) & Maximum (\%) & Minimum (\%) & Standare errors (\%) \\
\hline Hypersthene & 9.19 & 27.30 & 0.07 & 5.76 \\
gypsum & 12.00 & 37.61 & 0.04 & 14.55 \\
apatite & 7.38 & 33.79 & 0.11 & 8.65 \\
chlorite & 11.41 & 37.43 & 0.07 & 5.55 \\
siderite & 5.55 & 18.52 & 0.03 & 3.64 \\
geothite & 12.58 & 30.42 & 0.11 & 7.92 \\
Mixed sample 1 & 9.36 & 23.74 & 0.28 & 4.68 \\
Mixed sample 2 & 13.37 & 35.00 & 0.11 & 10.70 \\
Mixed sample 3 & 12.52 & 31.25 & 0.30 & 7.23 \\
Mixed sample 4 & 13.03 & 30.65 & 0.43 & 8.25 \\
Mixed sample 5 & 13.65 & 37.20 & 0.01 & 9.74
\end{tabular}
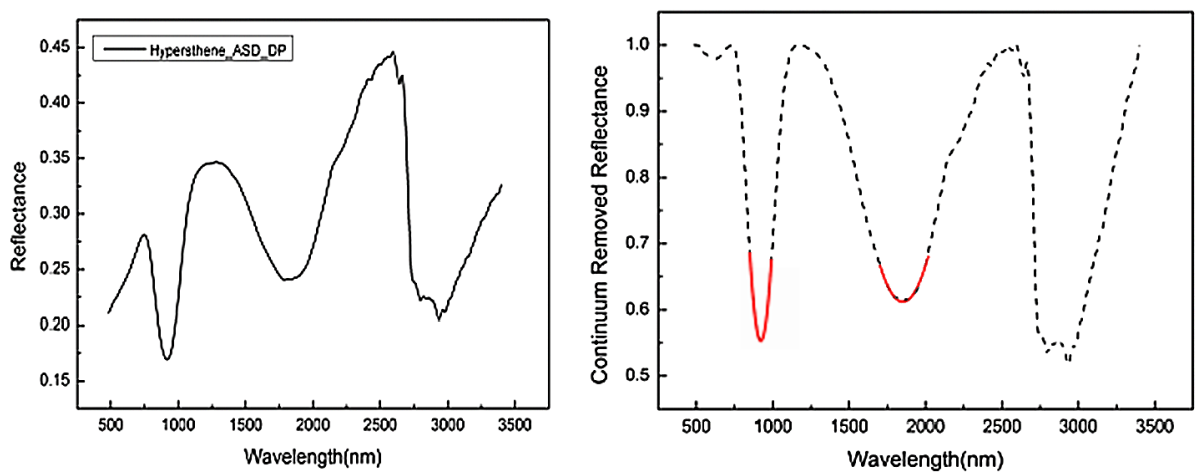

Fig. 7 The spectra of hypersthene and the parabola-fitting results for the 1- $\mu \mathrm{m}$ and 2- $\mu \mathrm{m}$ absorption-band positions. The red lines represent the wavelength ranges used for the parabola fitting and the absorption are the wavelengths corresponding to the minimum of the red lines

also shows many sharp absorption such as the $1.4 \mu \mathrm{m}, 1.9 \mu \mathrm{m}$ and 2.0 2.4 absorption features. Apatite has an $\sim 2.7 \mu \mathrm{m}$ sharp absorption due to hydroxyl groups. It also can be seen that the band centers of the mixtures near $1 \mu \mathrm{m}$ and $2 \mu \mathrm{m}$ shift towards longer wavelengths with the increasing augite contents. Besides, there are also enough bands in MMS hyperspectral modes for exhibiting $\sim 0.6 \mu \mathrm{m}, \sim 1.0 \mu \mathrm{m}, \sim 1.4 \mu \mathrm{m}, \sim 1.9 \mu \mathrm{m}, 2.0 \sim 2.4 \mu \mathrm{m}$ and $2.7 \sim 3.1 \mu \mathrm{m}$ absorption features of minerals. For the selected minerals, the deviations of the absorption band centers measured between MMS and the SCS varies from 0.69 to $14.86 \mathrm{~nm}$ (Table 6), which are acceptable within the limits of the spectral resolution. This demonstrated that different minerals can be effectively distinguished by MMS hyperspectral data.

\subsubsection{Analysis on Multispectral Data Quality and Absorption Characteristics}

Typical minerals, hypersthene and gypsum were selected to evaluate the multispectral data quality of MMS because of the $1 \mu \mathrm{m}$ and $2 \mu \mathrm{m}$ broad absorption features of hypersthene and 
Table 6 The absorption deviations of different mineral samples between MMS and the SCS

\begin{tabular}{llccc}
\hline Typical minerals & Absorption positions & MMS $(\mathrm{nm})$ & ASD_DP $(\mathrm{nm})$ & Deviation (nm) \\
\hline Hypersthene & $\sim 1000 \mathrm{~nm}$ & 926.61 & 917.38 & 9.23 \\
chlorite & $\sim 2000 \mathrm{~nm}$ & 1837.09 & 1826.03 & 11.06 \\
& $\sim 700 \mathrm{~nm}$ & 714.51 & 711.66 & 2.85 \\
& $\sim 900 \mathrm{~nm}$ & 891.26 & 890.46 & 0.8 \\
& $\sim 1400 \mathrm{~nm}$ & 1406.23 & 1400.58 & 5.65 \\
& $\sim 1900 \mathrm{~nm}$ & 1993.05 & 1982.58 & 10.47 \\
apatite & $\sim 2350 \mathrm{~nm}$ & 2347.27 & 2334.18 & 13.09 \\
gypsum & $\sim 2800 \mathrm{~nm}$ & 2828.58 & 2819.27 & 9.31 \\
& $\sim 1400 \mathrm{~nm}$ & 1459.51 & 1449.50 & 10.01 \\
& $\sim 1750 \mathrm{~nm}$ & 1768.25 & 1753.39 & 14.86 \\
& $\sim 1900 \mathrm{~nm}$ & 1955.14 & 1942.60 & 12.54 \\
geothite & $\sim 2250 \mathrm{~nm}$ & 2228.09 & 2215.22 & 12.87 \\
& $\sim 2500 \mathrm{~nm}$ & 2492.30 & 2491.61 & 0.69 \\
siderite & $\sim 1900 \mathrm{~nm}$ & 1967.64 & 1953.68 & 13.96 \\
& $\sim 2350 \mathrm{~nm}$ & 2333.08 & 2319.79 & 14.29 \\
& $\sim 2550 \mathrm{~nm}$ & 2540.01 & 2526.87 & 13.14 \\
& $\sim 2750 \mathrm{~nm}$ & 2770.82 & 2764.63 & 6.19 \\
& & & &
\end{tabular}

Fig. 8 The comparison between hypersthene's hyperspectral and various multispectral curves

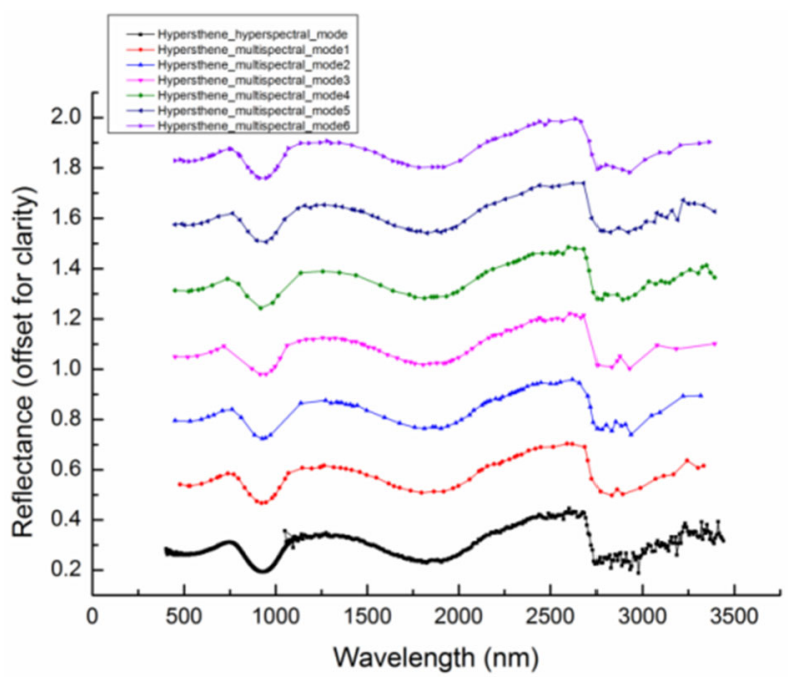

many narrow absorption features of gypsum. The numbers of the key bands and the bands distribution for the two selected minerals' absorption features characterization are analyzed to validate the effectiveness of multispectral bands selection of MMS. The absorption band center deviations between the multispectral data and the hyperspectral data are also calculated to evaluate the multispectral data quality.

Shown in Fig. 8 and Fig. 9 are the six sets of multispectral and one hyperspectral curves of the hypersthene and gypsum. We could see that the broad absorption features of hypers- 
Fig. 9 The comparison between gypsum's hyperspectral and various multispectral curves

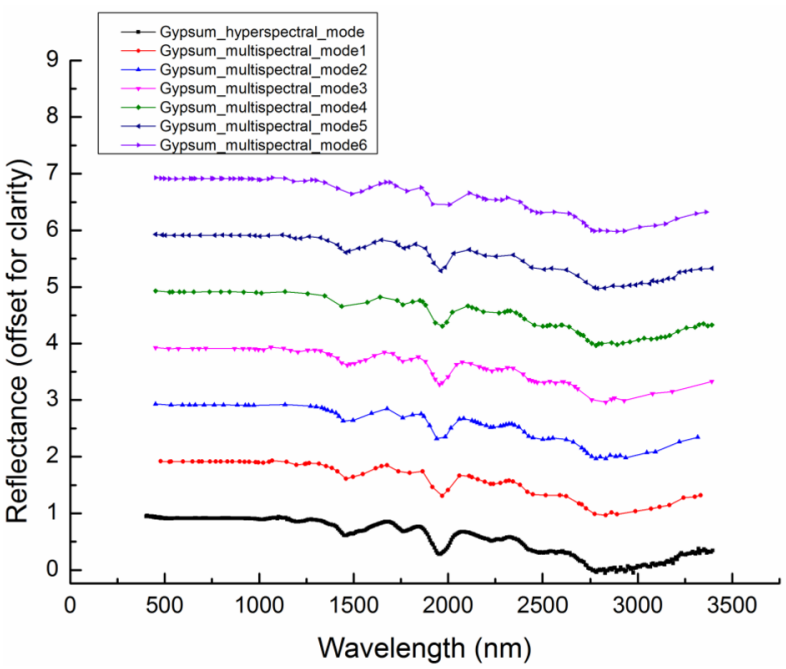

Table 7 The hypersthene's absorption band center deviations between various multispectral data and hyperspectral data of MMS

\begin{tabular}{llrrr}
\hline $\begin{array}{l}\text { Multispectral } \\
\text { modes }\end{array}$ & $\begin{array}{l}\text { Absorption } \\
\text { band centers }\end{array}$ & $\begin{array}{l}\text { Multispectral_absorption_ } \\
\text { band_centers (nm) }\end{array}$ & $\begin{array}{l}\text { Hyperspectral_absorption_ } \\
\text { band_centers (nm) }\end{array}$ & $\begin{array}{l}\text { Deviations } \\
(\mathrm{nm})\end{array}$ \\
\hline $\begin{array}{llrl}\text { Mode 1 } \\
\text { (versatile) }\end{array}$ & $\sim 1000 \mathrm{~nm}$ & 927.94 & 928.82 & 0.88 \\
Mode 2 & $\sim 2000 \mathrm{~nm}$ & 1810.95 & 1808.85 & 2.10 \\
(phyllosilicates) & $\sim 1000 \mathrm{~nm}$ & 927.89 & 928.82 & 0.93 \\
Mode 3 & $\sim 1000 \mathrm{~nm}$ & 1810.91 & 1808.85 & 2.06 \\
(sulfates) & $\sim 2000 \mathrm{~nm}$ & 1813.30 & 928.82 & 5.32 \\
Mode 4 & $\sim 1000 \mathrm{~nm}$ & 924.84 & 1808.85 & 4.45 \\
(Carbonates) & $\sim 2000 \mathrm{~nm}$ & 1802.23 & 928.82 & 3.98 \\
Mode 5 & $\sim 1000 \mathrm{~nm}$ & 927.53 & 1808.85 & 6.62 \\
(water salts) & $\sim 2000 \mathrm{~nm}$ & 1821.45 & 928.82 & 1.29 \\
Mode 6 & $\sim 1000 \mathrm{~nm}$ & 928.62 & 1808.85 & 12.60 \\
(oxides and & $\sim 2000 \mathrm{~nm}$ & 1808.28 & 928.82 & 0.20 \\
mafic silicates) & & & 1808.85 & 0.57 \\
\hline
\end{tabular}

thene are well exhibited by all the six sets of multispectral band combinations, but the mode 6 and the mode 1 can better capture the hypersthene's spectral features of $1 \mu \mathrm{m}$ and $2 \mu \mathrm{m}$ than other four modes since there are more bands distributed in these areas and the sampling intervals are more reasonable. Similar to the result of hypersthene, the narrow band absorption features of gypsum are well exhibited by all the six sets of band combinations. But the mode 3 and mode 1 can better reveal the narrow absorption features of gypsum than the other four modes, since the bands numbers and distribution for mode 3 and mode 1 seems to be more reasonable. Additionally, we compared the $1 \mu \mathrm{m}$ and $2 \mu \mathrm{m}$ absorption band center deviations of hypersthene between the multispectral and the hyperspectral data of MMS (Table 7), results indicate that the multispectral data of mode 6 (band combinations for iron oxide and silicate minerals) and mode 1 (versatile band combinations) have the lowest de- 
Table 8 Performance characteristics comparison between OMEGA, CRISM and MMS

\begin{tabular}{|c|c|c|c|}
\hline $\begin{array}{l}\text { Parameters } \\
\text { list }\end{array}$ & OMEGA & CRISM & MMS \\
\hline $\begin{array}{l}\text { Spectral } \\
\text { range }\end{array}$ & $0.35 \sim 5.1 \mu \mathrm{m}$ & $0.4 \sim 3.9 \mu \mathrm{m}$ & $0.379 \sim 3.425 \mu \mathrm{m}$ \\
\hline \multirow[t]{2}{*}{ Bands } & 352 & 544 (hyperspectral) & 576 (hyperspectral) \\
\hline & & 72 (multispectral) & 72 (multispectral) \\
\hline $\begin{array}{l}\text { Spatial } \\
\text { resolution }\end{array}$ & $4.1 \mathrm{~km} \sim 350 \mathrm{~m}$ & $\begin{array}{l}\text { Global mode: } 100 \sim 200 \mathrm{~m} \text {; } \\
\text { Target mode: } 36 \mathrm{~m} / 18 \mathrm{~m}\end{array}$ & $\begin{array}{l}\text { 26-sample: } \\
\text { 2.12 km@265 km; } \\
\text { 6.4 km@800 km; } \\
\text { 208-sample: 265 m@265 km; } \\
\text { 800 m@800 km; } \\
\text { Full frame: } \\
\text { 132.5 m@265 km; } \\
400 \text { m@800 km; } \\
\text { 104-sample: } 530 \text { m@265 km; } \\
\text { 1.6 km@800 km; } \\
\text { 52-sample: } \\
\text { 1.06 km@265 km; } \\
3.2 \text { km@800 km; }\end{array}$ \\
\hline $\begin{array}{l}\text { Sampling } \\
\text { intervals }\end{array}$ & $\begin{array}{l}7 \mathrm{~nm} @(0.35-1.00 \mu \mathrm{m}) \\
14 \mathrm{~nm} @(1.00-2.50 \mu \mathrm{m}) \\
20 \mathrm{~nm} @(2.50-5.1 \mu \mathrm{m})\end{array}$ & $\begin{array}{l}\text { Global Mode: } 5 * 5 \text { or } \\
10 * 10 \text { pixels binning, } \\
54 \mathrm{~nm} \text {; } \\
\text { Target Mode: } 6.55 \mathrm{~nm}\end{array}$ & $\begin{array}{l}\text { Hyperspectral mode: } \\
\text { 3/26-sample: } \\
\text { 2.73 nm@(0.379-1.076 } \mu \mathrm{m}) \text {; } \\
7.5 \mathrm{~nm} @(1.033-3.425 \mu \mathrm{m}) \\
\text { Multispectral mode: } \\
\text { 52/104/208-sample: } \\
\text { 5.46 nm@(0.379-1.076 } \mu \mathrm{m}) \\
15 \mathrm{~nm} @(1.033-3.425 \mu \mathrm{m})\end{array}$ \\
\hline $\begin{array}{l}\text { Spectral } \\
\text { resolution }\end{array}$ & & $\begin{array}{l}\text { V-NIR: } 7.9 \sim 10.1 \mathrm{~nm} ; \\
\text { N-MIR: } 9 \sim 19 \mathrm{~nm}\end{array}$ & $\begin{array}{l}\text { Hyperspectral mode: } \\
\text { 3/26-sample: } \\
3.51 \mathrm{~nm} @(0.379-1.076 \mu \mathrm{m}) \\
9.66 \mathrm{~nm} @(1.033-3.425 \mu \mathrm{m}) \\
\text { Multispectral mode: } \\
\text { 52/104/208-samples: } \\
\text { 7.02 nm@(0.379-1.076 } \mu \mathrm{m}) \text {; } \\
\text { 19.32 nm@(1.033-3.425 } \mu \mathrm{m}) \text {; }\end{array}$ \\
\hline
\end{tabular}

viations, and the deviations are less than $2.1 \mathrm{~nm}$, which are reasonable since the deviations are within the limits of the spectral resolution. The results illustrate that the bands selected for the different multispectral operation modes are reasonable and effective.

\section{Spectral Detection Capabilities Evaluation and Suggestions for In-Flight Detection}

\subsection{Parameters Comparison with OMEGA and CRISM}

Table 8 summarizes the main parameters among MMS, OMEGA and CRISM in terms of spectral range, number of bands, sampling intervals, spatial resolution and spectral resolution (He et al. 2021; Bibring et al. 2005; Murchie et al. 2007). It can be seen that the spectral range of MMS is lower than OMEGA and CRISM, but the band numbers of MMS hyperspectra mode is higher than CRISM and OMEGA. Besides, MMS has a slightly higher 
spatial resolution than OMEGA (265 m 2.12 km@265 km), but lower than that of CRISM. In terms of spectral resolution, The hyperspectral mode of MMS is comparable to that of CRISM, but the sampling intervals of MMS multispectral mode is better than the multispectral mode of CRISM.

\subsection{Spectral Detection Capabilities Evaluation and Discussion}

\subsubsection{Spectral Coverage}

Although the spectral coverage of MMS is lower than that of OMEGA and CRISM, it is still sufficient for identification and discrimination of many typical minerals' spectral features on the surface of Mars. For example, pyroxenes have two apparent absorption features centered around $1 \mu \mathrm{m}$ and $2 \mu \mathrm{m}$, which can be easily identified, and the band centers of pyroxene around $1 \mu \mathrm{m}$ and $2 \mu \mathrm{m}$ will shift towards longer wavelengths with increasing calcium contents. Besides, the absorptions of Low-Calcium Pyroxene (LCP) are centered at shorter wavelengths $(\sim 0.9$ and $1.8 \mu \mathrm{m})$ while the absorptions of High-Calcium Pyroxene (HCP) are centered at longer wavelengths $(\sim 1.05$ and $2.3 \mu \mathrm{m})$. Therefore, the enhancement of the spectral resolution helps to identify and distinguish LCP and HCP more efficiently. Olivine has a broad $(0.8 \sim 1.5 \mu \mathrm{m})$ and complex spectral absorption around $1 \mu \mathrm{m}$ (Centered at $\sim 1.05 \mu \mathrm{m}$ ). This complex absorption feature will also shift towards longer wavelengths as Fe content increases, which makes the type of the olivine changing from forsterite to fayalite (King and Ridley 1987; Cloutis and Gaffey 1991; Clark et al. 1993; Clenet et al. 2011). MMS is not only able to identify independently the minerals olivine, low-calcium and high-calcium pyroxenes, but also be able to better address the case of complex ternary mineral mixtures involving olivine and pyroxenes (e.g., Clenet et al. 2011, 2013). Ferric oxides on Mars exhibit distinct narrow absorption band near $0.6 \mu \mathrm{m}$ (Morris et al. 2000). Hydrated minerals exhibit absorption features near $\sim 1.4$ and $\sim 1.9 \mu \mathrm{m}$ caused by $\mathrm{O}-\mathrm{H}$ and/or $\mathrm{H}_{2} \mathrm{O}$ vibration absorption, and also show narrow absorption characteristics between $2.0 \sim 2.4 \mu \mathrm{m}$ resulting from the coupling between $\mathrm{OH} / \mathrm{H}_{2} \mathrm{O}$ to metal or to anionic complexes such as $\mathrm{SO}_{4}^{2-}$ and $\mathrm{CO}_{3}^{2-}$ (Bishop et al. 1993, 1994; Roush et al. 1993; Clark et al. 1990). Besides, The 2.0 2.4 $\mu \mathrm{m}$ absorption band centers of hydrated minerals varies with the type of minerals (Bishop et al. 1993, 1994; Roush et al. 1993; Bell et al. 1994; Cloutis et al. 2006). Water-containing sulfate minerals also have absorption characteristics caused by $S$ $\mathrm{O}$ stretching vibration, and the overtone absorptions exists between 2.2 and $2.5 \mu \mathrm{m}$, the accurate band centers of which are also changed with the varying element compositions (Cloutis et al. 2006). At last, $\mathrm{H}_{2} \mathrm{O}$ and $\mathrm{CO}_{2}$ in the Martian atmosphere show absorption characteristics around $1.25 \mu \mathrm{m}, 1.43 \mu \mathrm{m}, 1.5 \mu \mathrm{m}$ and $2 \mu \mathrm{m}$. The above-mentioned spectral characteristics are all within the detectable spectral range of MMS, which can be effectively identified and discriminated.

\subsubsection{Spectral Resolution and Bands Selection}

In order to distinguish minerals with similar spectral characteristics but have different geological indications, MMS is required to select reasonable numbers of bands and sampling intervals for discrimination of typical minerals' spectral characteristics on the Martian surface, and the spectral resolution of MMS should be as high as possible. Take montmorillonite and kaolinite as an example, these two kinds of minerals have similar spectral characteristics, but are formed in hydrothermal environments with different temperature conditions (Swayze et al. 2003). The requirements for the spectral resolution and sampling intervals for 

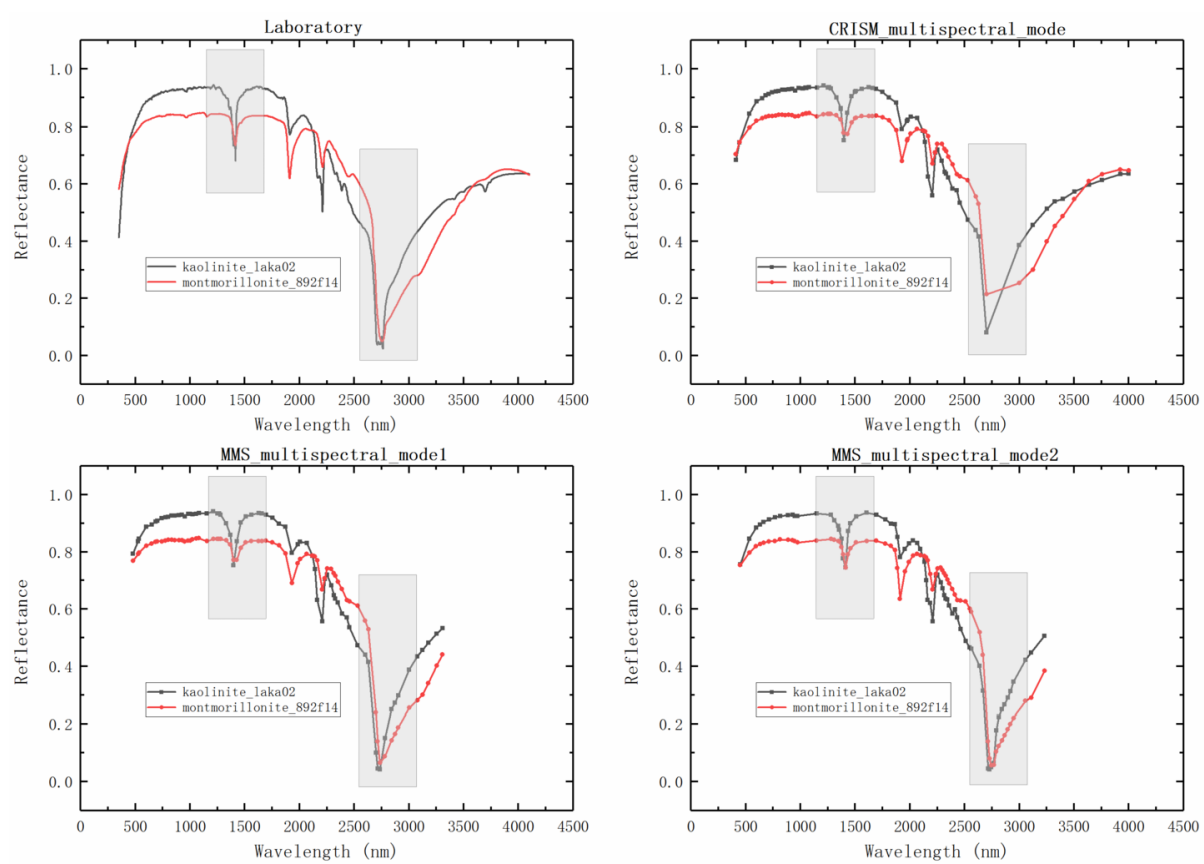

Fig. 10 Spectral resampling of kaolinite and montmorillonite. a) the typical laboratory spectra of kaolinite and montmorillonite selected from the USGS spectral library; b) spectral resampling of the kaolinite and montmorillonite laboratory spectra as the spectral resolution of the CRISM multispectral mode; c) spectral resampling of the kaolinite and montmorillonite laboratory spectra as the spectral resolution of the MMS multispectral mode 1 (the versatile bands combination); d) spectral resampling of the kaolinite and montmorillonite laboratory spectra as the spectral resolution of the MMS multispectral mode 2 (the bands combination for Phyllosilicate minerals)

discrimination of these two minerals are: $(1)<20 \mathrm{~nm}$ spectral resolution and (2) sampling at $\leq 20 \mathrm{~nm}$ sampling intervals (to ensure that at least 5 bands to characterize each spectral absorptions). CRISM's benchmark is to distinguish these two type of minerals (Murchie et al. 2007; Carter et al. 2013). From Table 8 we could see that OMEGA, CRISM hyperspectral mode and MMS hyperspectral mode could meet the requirements for montmorillonite and kaolinite discrimination. However, the CRISM global multispectral detection mode reduces the sampling intervals $(\sim 56 \mathrm{~nm})$ due to the combination and selection of bands, which resulted in a difficulty to accurately identify many water-bearing minerals, since the bands to characterize the absorption features are $\leq 4$ (Carter et al. 2013). As shown in Fig. 10, we have selected typical montmorillonite and kaolinite spectra from the USGS spectral library and resampled the spectra as the spectral resolutions of CRISM and MMS multispectral mode data. Due to the reduction in band numbers and the lower spectral resolution caused by bands combination, the CRISM multispectral mode data has deviations in the characterization of the spectral absorption of the two hydrated minerals near $1400 \mathrm{~nm}$ and $2750 \mathrm{~nm}$ (Fig. 10b), which hampers the precise discrimination of the two minerals. Figure 10c and Fig. 10d show that MMS multispectral mode 1 (the versatile bands combination) and mode 2 (the bands combination for Phyllosilicate minerals) can better express and distinguish the absorption characteristics of the two minerals, so the multispectral modes of MMS have slightly better detection capabilities than CRISM in the discrimination of water-bearing minerals. 
Fig. 11 The band settings of MMS multispectral mode 1 (versatile bands combination) for various typical minerals, included: silicate minerals (hypersthene), layered silicate minerals (chlorite, talc, vermiculite), sulfate minerals (gypsum), carbonate minerals (siderite), oxide minerals (Goethite) and hydrous minerals (apatite)

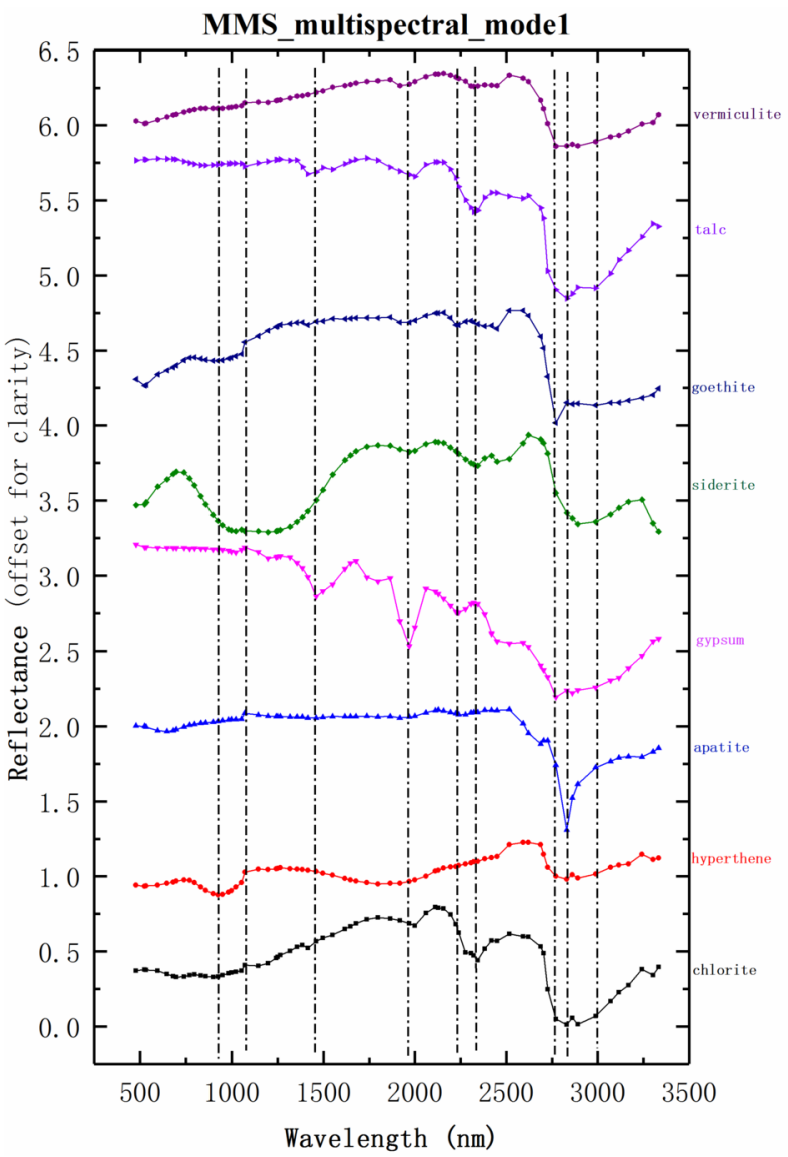

In addition, as a versatile bands combination, the MMS multispectral mode 1 selects at least 5 bands to describe each absorption characteristics (Fig. 11). This working mode could identify and distinguish various typical minerals effectively (Liu et al. 2018), and is suitable for global minerals mapping.

\subsubsection{Spatial Resolution}

OMEGA has covered $100 \%$ of the surface area of Mars with a spatial resolution of $4 \mathrm{~km} /$ pixel, but only covers $<10 \%$ of martian surface with a spatial resolution of $300 \mathrm{~m} /$ pixel; while CRISM has covered $80 \%$ of the Martian surface with a spatial resolution of $200 \mathrm{~m} /$ pixel, but only covers less than $1 \%$ of the Martian surface with the spatial resolution of $15 \mathrm{~m} /$ pixel. But MMS has its own characteristics in the spatial resolutions design. Its full-frame detection mode, 208-sample detection mode and 104-sample detection mode could achieve spatial resolutions of several hundreds meters (Table 8), which is slightly better than OMEGA (kilometers to hundreds of meters), but lower than CRISM (several hundreds meters to dozens of meters). Therefore, considering the coverage characteristics of OMEGA and CRISM, we could firstly make use of the MMS 208-sample or 104-sample multi-spectral detection mode 1 (versatile bands combination) to perform global 

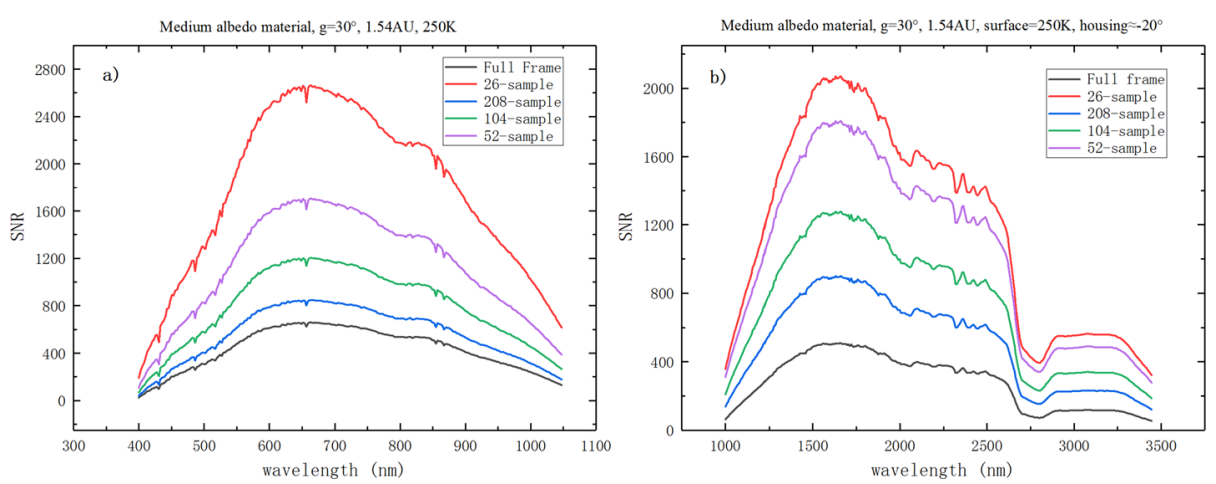

Fig. 12 The calculated results of the SNR curves in the V-NIR bands (a) and N-MIR bands (b) of MMS under different working modes. The integration time used for the V-NIR detector is $45 \mathrm{~ms}$, and the integration time used for the N-MIR detector is $23.04 \mathrm{~ms}$

mapping of martian surface with spatial resolution of hundreds of meters, especially focusing on the areas that CRISM has not yet covered to obtain typical minerals' distribution map of martian surface, and then select areas of interest to perform hyperspectral detection or other kinds of multispectral detection to obtain further subtle spectral changes and detail spatial distribution of typical minerals.

\subsubsection{SNR Analysis}

High SNR is an important guarantee for extracting Martian mineral information from high spatial and high spectral resolution spectral data. The SNR requirements for a martian typical mineral with a $1 \%$ absorption feature at $2300 \mathrm{~nm}$ should be at least higher than 400 (Murchie et al. 2007). The reason for choosing $2300 \mathrm{~nm}$ is that the absorption characteristic of this band is close to the absorption characteristics caused by $\mathrm{H}_{2} \mathrm{O}$ and $\mathrm{OH}$ in typical water-bearing minerals, which indicates the existence of water-bearing minerals, and the $1 \%$ spectral absorption depth is the criterion for evaluating the existence of water-bearing minerals (Murchie et al. 2007). According to the SNR requirements, we calculate the spectral SNR curves of each operation modes of MMS for a typical material spectrum on martian surface (Fig. 12). We selected the same SNR calculation parameters as CRISM. For example, the reflectance curves (10\%-20\%) of a typical area with medium reflectance characteristics on the surface of Mars is selected as the spectra of typical materials on the surface of Mars (Erard and Calvin 1997, Figure 3a), the distance from the sun to the surface area of Mars is set $1.54 \mathrm{AU}$, the surface temperature of Mars is $250 \mathrm{~K}$, and the solar phase angle is $30^{\circ}$.

Figure 12 shows the results of SNR under different working modes of MMS. Except for the full-frame working mode, all the other working modes have a SNR better than 400 in each band within the range of 500-2600 nm, which meets the SNR requirements for the detection of water-bearing minerals near $2300 \mathrm{~nm}$. The reason for the low SNR of $<500 \mathrm{~nm}$ and $>2600 \mathrm{~nm}$ data is mainly caused by the low reflectivity $(<10 \%)$ of the typical materials on the surface of Mars in these two spectral ranges. Therefore, for most martian surface with medium reflectance characteristics (10\%-20\%), and taking into account the spatial resolution, the 208-sample detection mode could be used. For areas with surface reflectance less than $10 \%$, the 104-sample or 52-sample detection mode could be used for detection. Although the full-frame detection mode fails to meet the requirement of SNR $>400$ near 


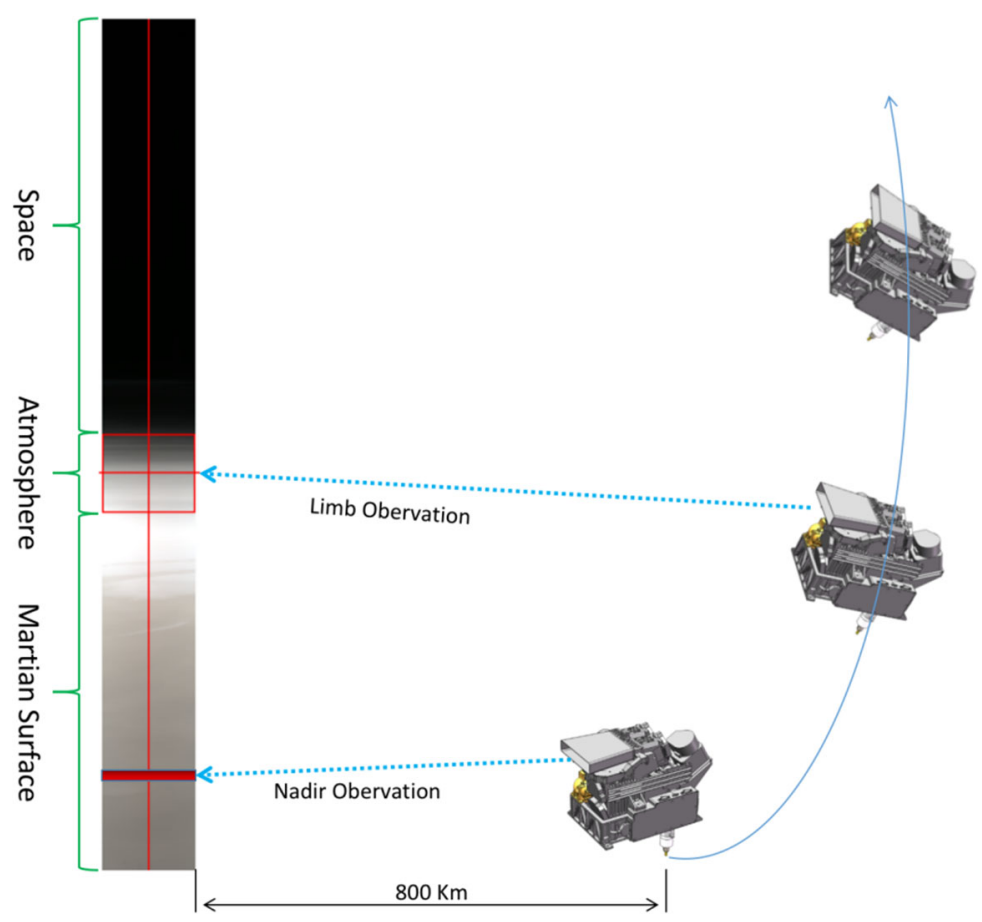

Fig. 13 Schematic diagram of the process by using MMS to perform limb observation of the Martian atmosphere. When the orbiter is flying from the perigee to the apogee and the orbital height exceeds $800 \mathrm{~km}$, the orbiter's working mode will be adjusted from Mars nadir observation to the sun orientation, MMS observation will be changed from Mars nadir observation to the direction away from the sun. During this process, the observation target of MMS will be changed from the surface of Mars to the atmosphere, and then to the cold space

$2300 \mathrm{~nm}$, it is also close to the SNR criterion of 400 . Therefore, for areas with high reflectivity ( $>20 \%$ ) on the surface of Mars, full-frame working mode could also be considered for detection, such as polar regions.

\subsection{Suggestions for In-Flight Detection}

Benefiting from OMEGA and CRISM's experience, and combined with the results of the validation experiment, MMS has formulated a set of preliminary observation plans including global mapping, target areas survey and atmospheric monitoring. Global mapping will focus on the distribution and relative proportions of the diagenetic minerals on Mars, the distribution characteristics of water-bearing minerals, and the discovery of new target areas. Considering the limitation of data transmission and downlink, the spatial continuous 52 or 104 sample multispectral detection mode are recommended for global mapping with the corresponding $4 \mathrm{~Hz}$ frame rate. Target areas survey will emphasize on the landing sites, areas of minerals abnormally distributed, and geomorphological sites with characteristic features such as large impact craters, sediment areas and volcanic areas. The recommended detection modes for target areas survey are spatial continuous 208-sample multispectral detection mode with high spatial resolution or spatial continuous 26-sample hyperspectral operation mode with high spectral resolution at the corresponding $8 \mathrm{~Hz}$ or $16 \mathrm{~Hz}$ frame rate. Atmospheric limb observation (atmospheric monitoring) will be performed at proper time to 
monitor spatial and temporal changes of $\mathrm{CO}_{2}, \mathrm{H}_{2} \mathrm{O}, \mathrm{CO}$ and other gases, and to accumulate data for the analysis of atmospheric composition. When the orbiter is flying from the perigee to the apogee and the orbital height exceeds $800 \mathrm{~km}$, the orbiter's working mode will be adjusted from Mars nadir observation to the sun orientation, MMS observation will be changed from Mars nadir observation to the direction away from the sun. During this process, the observation target of MMS will be changed from the surface of Mars to the atmosphere, and then to the cold space. Therefore, there is an opportunity for MMS to detect Martian atmosphere by limb observation using the recommended spatial continuous 26-sample hyperspectral detection mode (Fig. 13). Finally, MMS could also conduct joint observations with the medium and high-resolution cameras, expected to develop data fusion research, to obtain more data results, and to enrich the understandings of Mars.

Acknowledgements This work was supported by China's first Mars exploration program and China National Space Administration (CNSA), and was also funded by National Natural Science Foundation of China (NSFC) (Grant No. 11941002) and Key Laboratory of Space Active Opto-Electronics Technology, Shanghai Institute of Technical Physics, Chinese Academy of Sciences.

Author Contributions Study conception and design were performed by Bin Liu, Xin Ren, Dawei Liu, Jianjun Liu, Chunlai Li, Zhiping He and Rui Xu. Material preparation, Experiment implementation, data collection, and analysis were performed by Bin Liu, Xin Ren, Dawei Liu, Jianjun Liu, Qing Zhang, Hai Huang, Rui $\mathrm{Xu}$, Rong Wang and Chengyu Liu. The manuscript was written and edited by Bin Liu, Xin Ren, Dawei Liu, Jianjun Liu, Chunlai Li, Rui Xu, Zhiping He. All authors read and approved the final manuscript.

\section{Declarations}

Conflicts of Interest The authors declare that they have no conflicts of interest.

Open Access This article is licensed under a Creative Commons Attribution 4.0 International License, which permits use, sharing, adaptation, distribution and reproduction in any medium or format, as long as you give appropriate credit to the original author(s) and the source, provide a link to the Creative Commons licence, and indicate if changes were made. The images or other third party material in this article are included in the article's Creative Commons licence, unless indicated otherwise in a credit line to the material. If material is not included in the article's Creative Commons licence and your intended use is not permitted by statutory regulation or exceeds the permitted use, you will need to obtain permission directly from the copyright holder. To view a copy of this licence, visit http://creativecommons.org/licenses/by/4.0/.

\section{References}

J.F. Bell III, J.B. Pollack, T.R. Geballe, D.P. Cruikshank, R. Freedman, Spectroscopy of Mars from 2.04 to $2.44 \mathrm{~mm}$ during the 1993 opposition: absolute calibration and atmospheric vs. mineralogic origin of narrow absorption features. Icarus 111, 106-123 (1994)

J-P. Bibring, Y. Langevin, A. Gendrin, B. Gondet, F. Poulet et al., Mars surface diversity as revealed by the OMEGA/Mars Express observations. Science 307, 1576-1581 (2005)

J-P. Bibring, Y. Langevin, J.F. Mustard, F. Poulet, R. Arvidson et al., Global mineralogical and aqueous Mars history derived from OMEGA/Mars Express data. Science 312, 400-404 (2006)

J.L. Bishop, C.M. Pieters, R.G. Burns, Reflectance and Mossbauer spectroscopy of ferrihydritemontmorillonite assemblages as Mars soil analog materials. Geochim. Cosmochim. Acta 57, 4583-4595 (1993)

J.L. Bishop, C.M. Pieters, J.O. Edwards, Infrared spectroscopic analyses on the nature of water in montmorillonite. Clays Clay Miner. 42(6), 702-716 (1994)

J. Carter, F. Poulet, J-P. Bibring, N. Mangold, S. Murchie, Hydrous minerals on Mars as seen by the CRISM and OMEGA imaging spectrometers: updated global view. J. Geophys. Res., Planets 118, 831-858 (2013)

R.N. Clark, Reflectance spectra, in Rock Physics \& Phase Relations: A Handbook of Physical Constants, ed. by T.J. Ahrens. AGU Ref. Shelf, vol. 3 (AGU, Washington, 1995), pp. 178-188 
R.N. Clark, T.V.V. King, M. Klejwa, G.A. Swayze, N. Vergo, High spectral resolution reflectance spectroscopy of minerals. J. Geophys. Res. 95, 12653-12680 (1990)

R.N. Clark, G.A. Swayze, A. Gallagher, T.V.V. King, W.M. Calvin, The USGS, Digital Spectral Library: Version 1-0.2 to 3.0 mm, USGS, Open File Report 93-592 (1993)

H. Clenet, P. Pinet, Y. Daydou, F. Heuripeau, C. Rosemberg, D. Baratoux, S.D. Chevrel, A new systematic approach using the Modified Gaussian Model: insight for the characterization of olivine-pyroxene mixtures and minerals chemical compositions. Icarus 213, 404-422 (2011)

H. Clenet, P.C. Pinet, G. Ceuleneer, Y. Daydou, F. Heuripeau, C. Rosemberg, J-P. Bibring, G. Bellucci, F. Altieri, B. Gondet, A systematic mapping procedure based on the Modified Gaussian Model to characterize magmatic units from Olivine/Pyroxenes mixtures: application to the Syrtis Major volcanic shield on Mars. J. Geophys. Res., Planets 118, 1632-1655 (2013). https://doi.org/10.1002/Jgre.20112

E.A. Cloutis, M.J. Gaffey, Pyroxene spectroscopy revisited: spectral-compositional correlations and relationship to geothermometry. J. Geophys. Res. 96(E5), 22809-22826 (1991)

E.A. Cloutis, F.C. Hawthorne, S.A. Mertzman et al., Detection and discrimination of sulfate minerals using reflectance spectroscopy. Icarus 184, 121-157 (2006)

B.L. Ehlmann, C.S. Edwards, Mineralogy of the martian surface. Annu. Rev. Earth Planet. Sci. 42(1), 291-315 (2014). https://doi.org/10.1146/annurev-earth-060313-055024

S. Erard, W. Calvin, New composite spectra of Mars, 0.4-5.7 um. Icarus 130, 449-460 (1997)

V.C. Farmer, The layer silicates, in The Infra-Red Spectra of Minerals, ed. by V.C. Farmer (Mineral. Soc., London, 1974), pp. 331-364

Z.P. He, R. Xu, C.L. Li et al., Mars Mineralogical Spectrometer (MMS) on Tianwen-1 mission. Space Sci. Rev. 217, 27 (2021)

T.V.V. King, W.I. Ridley, Relation of the spectroscopic reflectance of olivine to mineral chemistry and some remote sensing implications. J. Geophys. Res. 92, 11457-11469 (1987)

C. Li, J. Liu, Y. Geng et al., Scientific objectives and payload configuration of China's first Mars exploration mission. J. Deep Space Explor. 5(5), 406-413 (2018)

B. Liu, C.L. Li, G.L. Zhang et al., Data processing and preliminary results of the Chang'e-3 VIS/NIR imaging spectrometer in-situ analysis. Res. Astron. Astrophys. 14(12), 1578-1594 (2014)

D.W. Liu, X. Ren, H.B. Zhang et al., Preliminary wavelengths selection for multispectral detection mode of Mars Mineral Spectrometer of China's First Mars Exploration, in European Planetary Science Congress, vol. 12 (2018), EPSC2018-574-2

P. Martin, P.C. Pinet, R. Bacon, A. Rousset, F. Bellagh, Martian surface mineralogy from 0.8-1.05 $\mu \mathrm{m}$ TIGER spectro-imagery measurements in Terra Sirenum and Tharsis Montes Formation. Planet. Space Sci. 44(8), 859-888 (1996)

R.V. Morris, D.C. Golden, J.F. Bell III et al., Mineralogy, composition, and alteration of Mars Pathfinder rocks and soils: evidence from multispectral, elemental, and magnetic data on terrestrial analogue, SNC meteorite, and Pathfinder samples. J. Geophys. Res. 105, 1757-1817 (2000)

S. Murchie et al., Compact Reconnaissance Imaging Spectrometer for Mars (CRISM) on Mars Reconnaissance Orbiter (MRO). J. Geophys. Res. 112, E05S03 (2007). https://doi.org/10.1029/2006JE002682

S.L. Murchie et al., Compact Reconnaissance Imaging Spectrometer for Mars investigation and data set from the Mars Reconnaissance Orbiter's primary science phase. J. Geophys. Res. 114, E00D07 (2009). https://doi.org/10.1029/2009JE003344

P. Pinet, S. Chevrel, Spectral identification of geological units on the surface of Mars related to the presence of silicates from earthbased near-infrared telescopic CCD imaging. J. Geophys. Res. 95(B9), 14435-14446 (1990)

T.L. Roush, D.L. Blaney, R.B. Singer, The surface composition of Mars as inferred from spectroscopic observations, in Remote Geochemical Analysis: Elemental and Mineralogical Composition, ed. by C.M. Pieters, P.A.J. Englert (Cambridge University Press, Cambridge, 1993), pp. 367-393

G.A. Swayze, R.N. Clark, A.F.H. Goetz, T.G. Chrien, N.S. Gorelick, Effects of spectrometer band pass, sampling, and signal-to-noise ratio on spectral identification using the Tetracorder algorithm. J. Geophys. Res. 108(E9), 5105 (2003). https://doi.org/10.1029/2002JE001975

C.E. Viviano, J.E. Moersch, H.Y. McSween, Implications for early hydrothermal environments on Mars through the spectral evidence for carbonation and chloritization reactions in the Nili Fossae region. J. Geophys. Res., Planets 118, 1858-1872 (2013)

P.J. Ye et al., Mission overview and key technologies of the first Mars probe of China. Sci. China, Technol. Sci. 60(5), 649-657 (2017). https://doi.org/10.1007/s11431-016-9035-5

Publisher's Note Springer Nature remains neutral with regard to jurisdictional claims in published maps and institutional affiliations. 


\section{Authors and Affiliations}

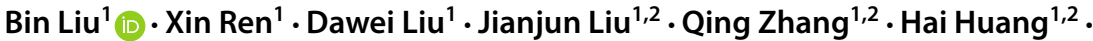

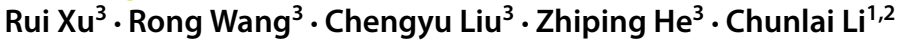

$\triangle X$. Ren

renx@nao.cas.cn

$凶$ D. Liu

liudw@nao.cas.cn

$\bigotimes$ J. Liu

liujj@nao.cas.cn

1 Key Laboratory of Lunar and Deep Space Exploration, National Astronomical Observatories, Chinese Academy of Sciences, Beijing 100101, China

2 University of Chinese Academy of Sciences, Beijing 100049, China

3 Key Laboratory of Space Active Opto-electronics Technology, Shanghai Institute of Technical Physics, Chinese Academy of Sciences, Shanghai 200083, China 